\title{
ASPECTOS BIOLÓGICOS E TÉCNICA DE CRIAÇÃO DO GORGULHO-DA-GOIABA, Conotrachelus psidii MARSHALL (COLEOPTERA: CURCULIONIDAE) ${ }^{1}$
}

\author{
FABRICIO IGLESIAS VALENTE², VERA LÚCIA RODRIGUES MACHADO BENASSI ${ }^{3}$
}

RESUMO-Considerada praga-chave da cultura da goiaba, Conotrachelus psidii Marshall (Coleoptera: Curculionidae) tem causado grandes prejuízos em vários países produtores desta fruta. A pesquisa objetivou avaliar os parâmetros biológicos da praga, sob condições controladas, através do desenvolvimento de uma técnica de criação que permitiu efetuar observações diárias de pré-pupas e pupas. Constatou-se que o substrato adequado para manutenção dessas fases foi o solo argiloso umedecido com viabilidade de $78 \%$, sendo este o tipo de solo utilizado na técnica de criação, que foi desenvolvida para trabalhos em câmara climatizada, à temperatura constante de $25 \pm 1^{\circ} \mathrm{C}$, fotoperíodo de 12 horas e UR de $70 \% \pm 10 \%$. Quanto aos aspectos biológicos, a duração média do período de ovo, larva, pré-pupa, pupa e ovo-pupa foi de: 4,25; 12,2; 106,6; 14,88 e 138,4 dias, respectivamente. A duração média do período da fase adulta, no solo, início da alimentação, pré-oviposição, longevidade e pós-oviposição foi de, 22;11; 51,9; 149,32 e 7,18 dias, respectivamente. O período médio de oviposição foi de 120,27 dias, com um número médio de 343,63 ovos por fêmea. A técnica de criação desenvolvida permitiu acompanhar diariamente o desenvolvimento de pré-pupas, pupas e adultos do gorgulho-da-goiaba, sem que eles necessitassem reconstruir nova câmara, mostrando ser menos estressante e onerosa do ponto de vista energético.

Termos para indexação: Goiabeira, biologia, comportamento.

\section{BIOLOGICAL ASPECTS AND TECHNICAL REARING OF GUAVA WEEVIL, Conotrachelus psidii MARSHALL (COLEOPTERA: CURCULIONIDAE)}

\begin{abstract}
The species Conotrachelus psidii Marshall (Coleoptera: Curculionidae), considered a key pest of guava cultivation, is causing major damage in several producing countries of the fruit. The purpose of this study was to evaluate the biological parameters of the pest under controlled conditions, through the development of a rearing technique of pre-pupae and pupae that would allow daily observations. It was found that the substrate for an appropriate development of these phases was moistened clay soil (with survival rate of $78 \%$ ). This soil type was used in the rearing method, which was developed to work in a climatic chamber at a constant temperature of $25 \pm 1^{\circ} \mathrm{C}, 12 \mathrm{~h}$ photoperiod and $70 \% \mathrm{RH} \pm 10 \%$. The biological stages of the egg, larva, pre-pupa, pupa and egg-pupa lasted, on average, 4.25, 12.2, 106.6, 14.88, and 138.4 days, respectively. The adult stages in the soil, beginning of feeding, pre-oviposition, longevity, and post-oviposition lasted on average 22, 11, 51.9, 149.32, and 7.18 days, respectively. The average oviposition period lasted 120.27 days, with an average of 343.63 eggs per female. By the proposed rearing method, the development of pre-pupae, pupae and adults of the guava weevil could be daily monitored, without requiring the construction of a new chamber by the insects, thus reducing stress and input in terms of energy.
\end{abstract}

Index terms: Guava, biology, behavior.

${ }^{1}$ (Trabalho 213-13). Recebido em: 20-5-2013. Aceito para publicação em: 25-02-2014.

${ }^{2}$ Biólogo. - Mestrando em Entomologia Agrícola - FCAV/Unesp, Câmpus de Jaboticabal - Via de Acesso Prof. Paulo Donato Castellane, s/n., 14.884-900 Jaboticabal-SP - Brasil. E-mail: fabriciocbia@gmail.com

${ }^{3}$ Doutora em Entomologia, INCAPER, Linhares, ES. E-mail: vbenassi@incaper.es.gov.br 


\section{INTRODUÇ̃̃O}

Com a boa adaptação a diferentes tipos de clima e solo, atualmente, a produção de goiaba ocorre em todas as regiões tropicais e subtropicais (PAIVA et al.,1995).

Dentre os principais fatores que limitam a produção e a exportação de goiaba, destacase a espécie Conotrachelus psidii Marshall, 1922 (Coleoptera: Curculionidae), popularmente conhecida como gorgulho-da-goiaba, considerada praga-chave da cultura em vários países produtores de goiaba na América do Sul, como Peru, Venezuela, Colômbia e Brasil (MARTÍNEZ; CÁSARES, 1981; MONROY; INSUASTY, 2006; VASQUEZ et al., 2002).

As posturas do gorgulho são feitas nos frutos ainda verdes, sendo que as larvas, após a eclosão, passam a alimentar-se das sementes e, quando completamente desenvolvidas, caem ao solo e enterram-se. Constroem uma câmara, na qual permanecem até se tornarem adultas (MONROY; INSUASTY, 2006).

Devido à ausência de produtos químicos registrados para o controle do gorgulho-da-goiaba (AGROFIT, 2013), estudos sobre sua criação, biologia, comportamento e ecologia propiciam conhecimentos imprescindíveis para a elaboração de métodos de controle eficientes e menos agressivos à cultura (KOYAMA et al., 2004).

Considerando-se a escassez de estudos detalhados sobre a biologia do gorgulho, dificultada pela ausência de técnicas de criação eficientes que possibilitem observações diárias, o trabalho visou a desenvolver uma metodologia eficaz para a manutenção de pré-pupas e pupas da praga e, a partir dessa, determinar os aspectos biológicos.

\section{METODOLOGIA}

\footnotetext{
Obtenção dos exemplares de Conotrachelus psidii e estabelecimento de uma criação- estoque

Os primeiros exemplares de C. psidii foram coletados em um banco de germoplasma pertencente à Estação Experimental Filogônio Peixoto (ESFIP), localizada no Município de Linhares, Estado do Espírito Santo, Brasil (19º-24'50.20' S; 4003'56.50" W, altitude de 28 metros).

Para a coleta dos adultos, foi colocado um tecido branco sob a copa das goiabeiras, sendo os galhos das plantas agitados, a fim de que os indivíduos presentes nas plantas caíssem sobre o pano, onde eram coletados. Para a obtenção de
}

indivíduos imaturos, foram coletados frutos com lesões típicas de oviposição.

Em laboratório, os adultos foram acondicionados em frascos plásticos tampados com tecido voil, no interior dos quais eram colocados, diariamente, frutos de goiaba para a oviposição. Os frutos com lesões foram mantidos em bandejas plásticas até a saída das larvas desenvolvidas, que foram utilizadas nos ensaios de avaliação do tipo e textura de solos para a manutenção das fases de pré-pupa e pupa.

Para a confirmação da espécie, alguns exemplares adultos foram enviados ao especialista.

Desenvolvimento da técnica para a manutenção de pré-pupas e pupas do gorgulho

Para o desenvolvimento da técnica de manutenção das pré-pupas e pupas da praga, inicialmente, foram testadas as viabilidades dessas fases em três diferentes tipos de solo: arenoso, arenoargiloso e argiloso, com dois níveis de hidratação (saturado e úmido). O delineamento experimental utilizado foi o inteiramente casualizado, com seis tratamentos, em cinco repetições, sendo cada repetição representada por dez larvas do gorgulho. Os solos esterilizados foram colocados em frascos plásticos medindo $6,8 \mathrm{~cm}$ de diâmetro por $9,4 \mathrm{~cm}$ de altura, com orifícios em sua base, contendo uma camada de 7,0 cm de solo e tampados com tecido voil.

Os tratamentos denominados saturados foram mantidos com a capacidade máxima de água, inspecionados diariamente, enquanto os úmidos receberam $30 \mathrm{~mL}$ de água a cada dez dias. Os frascos permaneceram à temperatura ambiente e, após um período de sessenta dias, procedeu-se à retirada dos substratos, coletando-se os insetos para o cálculo dos índices de viabilidade e constatação dos estágios de desenvolvimento. Os resultados foram submetidos à análise da variância, e as médias, comparadas pelo teste de Tukey, ao nível de 5\% de probabilidade.

A partir do resultado obtido na etapa anterior, procedeu-se à elaboração das câmaras de criação das pré-pupas e pupas do solo, utilizando-se de solo argiloso esterilizado, umedecido com água destilada. Foram separadas pequenas porções do solo com cerca de $13 \mathrm{~g}$, as quais foram moldadas manualmente, formando esferas, semelhantes a "pequenas bolas", achatadas na base.

No centro das esferas, foi feito um orifício, através da introdução de um lápis até a metade da sua altura, obtendo-se, assim, a câmara de criação artificial propriamente dita (Figura 1A). Cada estrutura apresentou as seguintes dimensões: $2,7 \mathrm{~cm}$ 
de diâmetro e 2,1 cm de altura, com o orifício central medindo, aproximadamente, $1,0 \mathrm{~cm}$ de profundidade. Para impedir a entrada de luz, uma pequena esfera de argila tampava o orifício central (Figura 1B).

Assim que saía do fruto, cada pré-pupa era colocada em uma câmara de criação, permanecendo até a fase adulta (Figuras $1 \mathrm{C}$ e 1D). Para que as câmaras não ressecassem, sua umidade era monitorada e, sempre que necessário, elas eram umedecidas com borrifador manual.

Para acomodar as unidades de criação, foram utilizadas caixas tipo Gerbox forradas com papelfiltro, onde foi possível criar um microambiente capaz de evitar uma evaporação excessiva, condicionando uma distribuição uniforme da unidade entre as câmaras (Figura 1B).

Determinação dos aspectos biológicos de

\section{Conotrachelus psidii}

Para o estudo da biologia do inseto, utilizouse uma câmara climatizada com temperatura constante de $25 \pm 1^{\circ} \mathrm{C}$, fotoperíodo de 12 horas e UR de $70 \% \pm 10 \%$.

Inicialmente, foram individualizados dez casais obtidos da criação-estoque, colocados em frascos plásticos tampados com tecido voil. Diariamente, foram fornecidos frutos verdes de goiaba para a realização das posturas. No entorno dos pontos de postura, foi feito um corte com um estilete, mantendo-se a abertura fechada com uma tira de fita adesiva. Este procedimento possibilitou acompanhar a duração dos períodos de ovo e larva. Após o desenvolvimento completo destas, procedeuse a sua transferência para as câmaras de criação artificial, onde foram mantidas até a fase adulta.

Verificou-se, diariamente, o teor de umidade das unidades de criação e, sempre que necessário, aplicava-se água destilada, utilizando um pulverizador manual com capacidade de $500 \mathrm{~mL}$.

Os adultos emergidos foram individualizados em frascos plásticos, fornecendo-lhes frutos, flores e folhas de goiabeira para alimentação e oviposição.

Devido à dificuldade encontrada para determinar o sexo dos indivíduos sem causar injúria nos insetos, foi adotado o seguinte procedimento: após o início da alimentação, os adultos tiveram um dos élitros marcado com esmalte de cores distintas e unidos em frascos plásticos em grupos de oito indivíduos para possibilitar o acasalamento. Assim que era constatada uma oviposição, os gorgulhos adultos eram individualizados em potes com novos frutos, e isso permitia certificar qual fêmea havia ovipositado, porque no dia seguinte uma nova postura era realizada apenas em um dos frascos. Os demais indivíduos eram reagrupados, e a fêmea fecundada era mantida separada para determinar os períodos de pré-oviposição, pós-oviposição e capacidade de postura.

\section{RESULTADOS E DISCUSSÃO}

\section{Técnica para a manutenção de pré-pupas e pupas do gorgulho}

Os índices de viabilidade de pré-pupas de $C$. psidii, obtidos nos diferentes substratos, encontramse relacionados na Tabela 1 .

A ação conjunta da textura dos substratos e da umidade influenciou na sobrevivência do gorgulho. Após um período de sessenta dias da inoculação das larvas, obteve-se o maior índice de viabilidade (78\%) no solo argiloso umedecido, o qual diferiu, estatisticamente, apenas do índice obtido no arenoargiloso umedecido (24\%) e na areia saturada (36\%) (Tabela1). Valor de viabilidade inferior a estes $(33,3 \%)$ foi encontrado por Bailez et al. (2003), quando mantiveram pré-pupas de C.psidii em areia, os quais atribuíram a alta mortalidade, provavelmente, à secagem excessiva do substrato.

$\mathrm{O}$ excesso de água dificultou a penetração das larvas nos substratos saturados; além disso, principalmente na areia, elas encontraram dificuldade para a construção das câmaras para permanência nos estágios de pré-pupa e pupa. Esses resultados, provavelmente, podem ser atribuídos à porosidade dos solos, pois, de acordo com Saxton e Rawls (2006), os solos argilosos (mais porosos) tornam-se muito pegajosos quando muito úmidos, e os arenosos (menos porosos) ficam mais pesados, o que exigiu maior esforço das larvas, debilitando-as.

Também, Martínez e Cásares (1981) relataram que a penetração das larvas é, certamente, dependente da textura e da umidade do solo, ao observarem, em condições de campo, que $15,6 \%$ das diferentes fases de $C$. psidii se encontravam a uma profundidade entre 4 e $6 \mathrm{~cm} ; 78 \%$ entre 6 e $12 \mathrm{~cm}$, e $6,25 \%$ entre 12 e $15 \mathrm{~cm}$, embora não tenham relatado o tipo de solo da região.

A maior porcentagem de mortalidade das larvas inoculadas na areia saturada foi provocada por fungos, quando comparadas com a argila. Esse fato deve ter ocorrido, possivelmente porque, além de precisarem de mais tempo para a construção das câmaras, estas eram menos elaboradas, permitindo maior exposição dos insetos aos microrganismos.

Nos tratamentos úmidos, a taxa de viabilidade observada na areia $(60,0 \%)$ foi menor que a encontrada na argila úmida $(78 \%)$, resultando em maior ressecamento e, consequentemente, prejudicando 
a viabilidade dos insetos. Isso pode ter ocorrido, provavelmente, devido à maior permeabilidade da areia em relação à argila, favorecendo a ação de microrganismos entomopatogênicos (SAXTON; RAWLS, 2006).

O tempo para o desenvolvimento das prépupas também foi influenciado pelos tipos de solos e umidades. Após os dois meses da inoculação, constatou-se que, do total de insetos obtidos dos frascos com a argila saturada, 88,5\% deles encontravam-se na fase de pré-pupa e $11,5 \%$ de pupa, enquanto, na areia saturada, 100\% eram prépupas. Na argila úmida, observaram-se os índices de $82 \%$ e $18 \%$, respectivamente, nas fases pré-pupal e pupal, valores semelhantes aos observados na areia úmida: $83,3 \%$ (pré-pupas) e 16,7\% (pupas). As características dos solos afetaram as pré-pupas, confirmando que insetos subterrâneos ou que passam alguma fase do ciclo biológico no interior do solo, têm seu desenvolvimento e biologia influenciados pela umidade e textura do solo no qual se encontram (PEREIRA et al., 2005; VIANA; COSTA, 1995).

Aspectos biológicos de Conotrachelus psidii

Observações diárias possibilitaram verificar que, para a realização das posturas, as fêmeas de C. psidii perfuram o epicarpo dos frutos de goiaba com seu aparelho bucal e constroem uma câmara no mesocarpo, atingindo, em média, uma profundidade e diâmetro de $2 \mathrm{~mm}$. Após a oviposição, o orifício central é fechado com os restos da alimentação e fezes do adulto.

A oviposição endofítica pode ser determinante para a viabilidade dos ovos, pois há uma barreira física que os protege das intempéries climáticas, dos possíveis danos mecânicos como gotas de chuva, vento, atuando também na defesa contra a ação de fungos entomopatogênicos, ácaros, outros predadores e possíveis parasitoides.

Os ovos apresentam forma elíptica e coloração leitosa, com comprimento médio de 1,1 mm e largura média de $0,70 \mathrm{~mm}$.

A duração média do período de incubação dos ovos de $C$. psidii foi de 4,2 dias $\pm 0,038$ dia (Tabela 2 ), valor este semelhante aos encontrados por Bailez et al. (2003) e Monroy e Insuasty (2006), que foram de 3,9 e 5,5 dias, respectivamente.

As larvas, assim que eclodem, possuem coloração esbranquiçada; entretanto, se a polpa do fruto for vermelha, elas apresentam coloração amarelada. Logo após a eclosão, apresentam comprimento médio de $1,5 \mathrm{~mm}$, e quando completamente desenvolvidas, $1,1 \mathrm{~cm}$.

A duração média do período larval foi de 12,2 $\pm 0,219$ dias (Tabela 2). Esse valor foi menor que o obtido por Bailez et al. (2003) de 16,0 $\pm 0,58$ dias. Esta diferença pode estar relacionada à qualidade do alimento fornecido às larvas, pois, segundo esses autores, estas foram alimentadas com fatias de goiaba, fato que pode ter modificado as propriedades do alimento através da oxidação da polpa exposta, ou mesmo estressado as larvas.

Em campo, após o completo desenvolvimento das larvas no interior dos frutos de goiaba, elas os abandonam, caindo ao solo, onde constroem uma câmara, a uma profundidade média de $6 \mathrm{~cm}$, passando aí os estágios de pré-pupa e pupa. Em laboratório, depois de terem saído dos frutos, as larvas foram colocadas nas câmaras artificiais de criação. A duração média do período pré-pupal obtido nessa condição foi de 106,6 \pm 3,023 dias (Tabela 2), média inferior à obtida por Bailez et al. (2003), de 142 dias, quando utilizaram solo arenoso para o confinamento das larvas.

Entretanto, o período pupal apresentou uma duração média de 14,8 \pm 0,597 dias, semelhante ao resultado encontrado por Bailez et al. (2003), que foi de 16 dias, valores que divergiram de Monroy e Insuasty, (2006), que registraram duração média de 50 dias para essa fase.

A duração média do período ovo-pupa foi de 138,4 dias, determinado a partir da oviposição até a emergência do adulto (Tabela 2).

O escurecimento e a quitinização completa do exoesqueleto dos adultos foram verificados do terceiro ao quinto dia após sua emergência. Estes permaneceram no solo por um período médio de 22 dias, em um intervalo de sete a 46 dias. Os adultos, após sairem do solo, começaram a alimentar-se após 11 dias, em média, com uma variação de quatro a 34 dias.

A duração média do período de pré-oviposição foi de 51,9 dias, com mínimo de 32 e máximo de 74 dias (Tabela 3). No início das posturas, as fêmeas não colocavam os ovos de forma regular, ou seja, em alguns dias não ovipositavam, enquanto, em diversas vezes, muitos ovos eram postos em um único dia. $\mathrm{O}$ maior número de posturas realizadas por uma fêmea, em um único dia, foi de 24 ovos, valor elevado para uma média diária de 2,85 ovos. Depois de um período, em torno de 30 dias, as oviposições passaram a ser mais regulares. O período médio de oviposição foi de 120,27 dias, com um número médio de 343,63 ovos por fêmea. A fềmea com maior número de posturas permaneceu ativa por 211 dias e ovipositou 778 ovos.

O período de pós-oviposição apresentou média de 7,18 dias, variando de 0 a 17 dias. Apesar de 
o período de pós-oviposição parecer curto, a maioria das fêmeas, antes do término total das oviposições, retornaram a fazer posturas de forma irregular e até fora das câmaras que elas construíam (Tabela 3).

A média semanal de ovos por fêmea apresentou dois períodos de maior número de postura, o primeiro, com duração até a quarta semana, e o segundo, entre a décima oitava e a vigésima segunda semana. $\mathrm{O}$ baixo número de posturas entre a oitava e a décima quarta semana pode ser uma característica comum da espécie, ou por influência pela grande variação do período de postura entre as fêmeas, que variou de 45 a 223 dias de atividade (Figura 2).
A longevidade média dos adultos foi de 149,32 dias. O ciclo total do gorgulho teve duração média de 302,59, variando de 133 a 749 dias.

Foram constatados poucos inimigos naturais de $C$. psidii em laboratório, com ocorrência de fungos entomopatogênicos, como Beauveria sp. e Metarhizium sp., ambos infectando larvas, porém adultos foram contaminados apenas por Beauveria sp.

TABELA 1- Viabilidades médias (\%) e intervalos de variação (\%) dos índices de viabilidade de pré-pupas de Conotrachelus psidii, mantidas em diferentes substratos, em condições de laboratório.

\begin{tabular}{lcc}
\hline \multicolumn{1}{c}{ Tratamentos } & Média de viabilidade (\%) & Intervalos de variação (\%) \\
\hline Argila saturada & $52,0 \mathrm{ab}$ & $30-80$ \\
Argila úmida & $78,0 \mathrm{a}$ & $60-100$ \\
Arenoargiloso saturado & $44,0 \mathrm{ab}$ & $25-70$ \\
Arenoargiloso úmido & $24,0 \mathrm{~b}$ & $10-60$ \\
Areia saturada & $36,0 \mathrm{~b}$ & $10-70$ \\
Areia úmida & $60,0 \mathrm{ab}$ & $30-90$ \\
\hline
\end{tabular}

* Médias seguidas pela mesma letra na vertical não diferem significativamente entre si, pelo teste de Tukey, a 5\% de probabilidade.

TABELA 2- Duração média ( $\pm \mathrm{EP})$ em dias das fases de desenvolvimento de Conotrachelus psidii, à temperatura constante de $25 \pm 1^{\circ} \mathrm{C}$, UR de $70 \pm 10 \%$ e fotofase de 12 horas.

\begin{tabular}{lcc}
\hline Fases de desenvolvimento & Intervalo de variação (dias) & Duração média (dias) \\
\hline Ovo & $2-7$ & $4,25 \pm 0,038(\mathrm{n}=476)^{*}$ \\
Larva & $9-19$ & $12,20 \pm 0,219(\mathrm{n}=214)$ \\
pré-pupa & $63-224$ & $106,60 \pm 3,023(\mathrm{n}=154)$ \\
Pupa & $8-40$ & $14,88 \pm 0,597(\mathrm{n}=122)$ \\
ovo-pupa & $97-188$ & $138,40 \pm 3,310(\mathrm{n}=47)$ \\
\hline
\end{tabular}

*n= número de insetos avaliados.

TABELA 3-Duração média ( $\pm \mathrm{EP})$ em dias dos parâmetros da fase adulta de Conotrachelus psidii, à temperatura constante de $25 \pm 1^{\circ} \mathrm{C}$, UR de $70 \pm 10 \%$ e fotofase de 12 horas.

\begin{tabular}{lcr}
\hline Fases de desenvolvimento & Intervalo de variação (dias) & Duração média (dias) \\
\hline Permanência no solo & $7-46$ & $22,00 \pm 3,19(\mathrm{n}=14)^{*}$ \\
Início da alimentação & $4-34$ & $11,00 \pm 1,93(\mathrm{n}=14)$ \\
Pré-oviposição & $32-74$ & $51,90 \pm 3,64(\mathrm{n}=11)$ \\
Longevidade & $39-271$ & $149,32 \pm 13,52(\mathrm{n}=47)$ \\
Pós-oviposição & $0-17$ & $7,18 \pm 1,61(\mathrm{n}=11)$ \\
\hline
\end{tabular}

$*_{\mathrm{n}}=$ número de insetos avaliados 


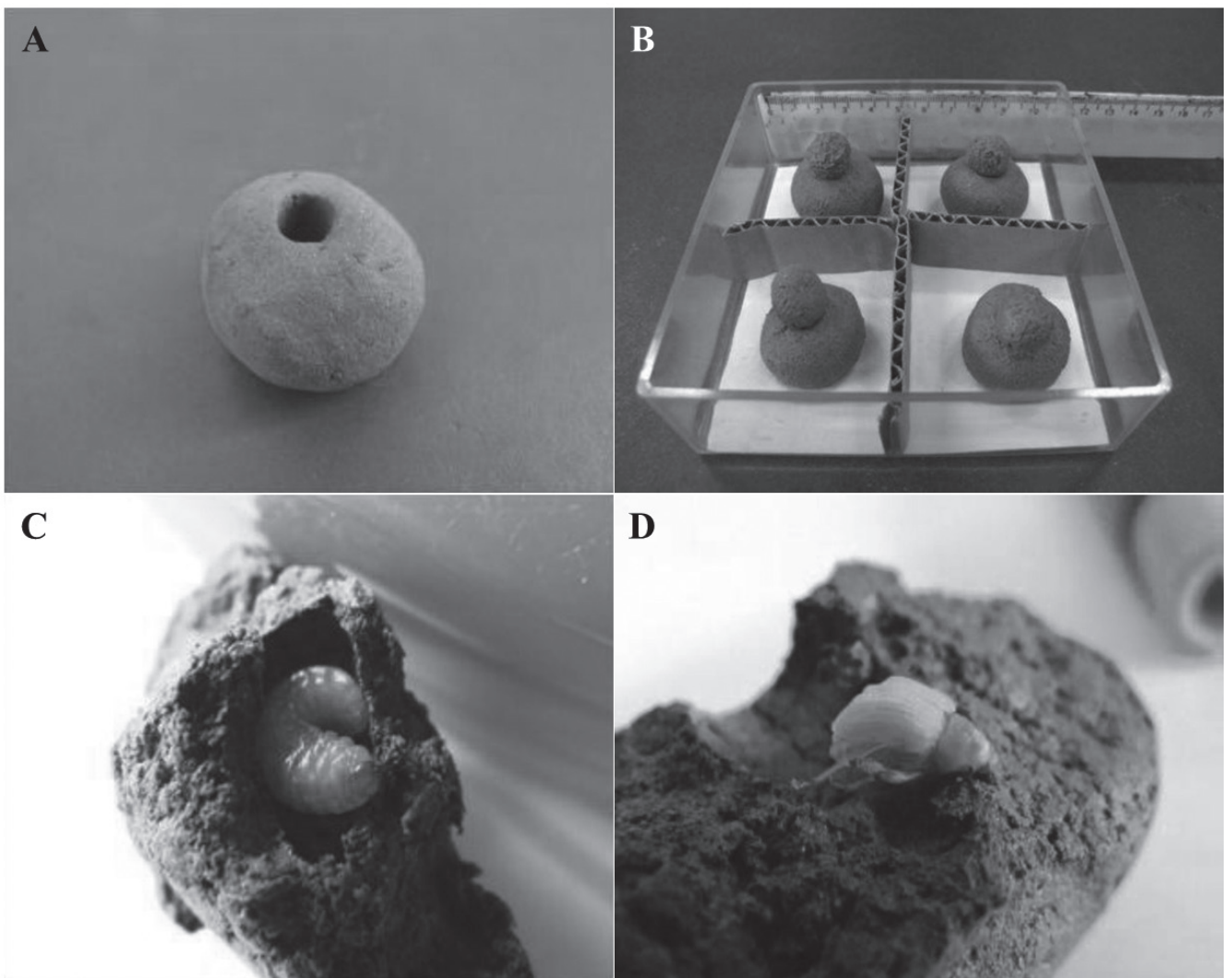

FIGURA 1 - Figuras esquemáticas das unidades de criação de Conotrachelus psidii . (A) Câmara de criação artificial aberta; (B) Unidades de criação fechadas dentro da Gerbox forrada de papel-filtro; (C) Pré-pupa no interior da unidade de criação; (D) Indivíduo no interior da câmara de criação artificial em seu primeiro dia no estágio de adulto.

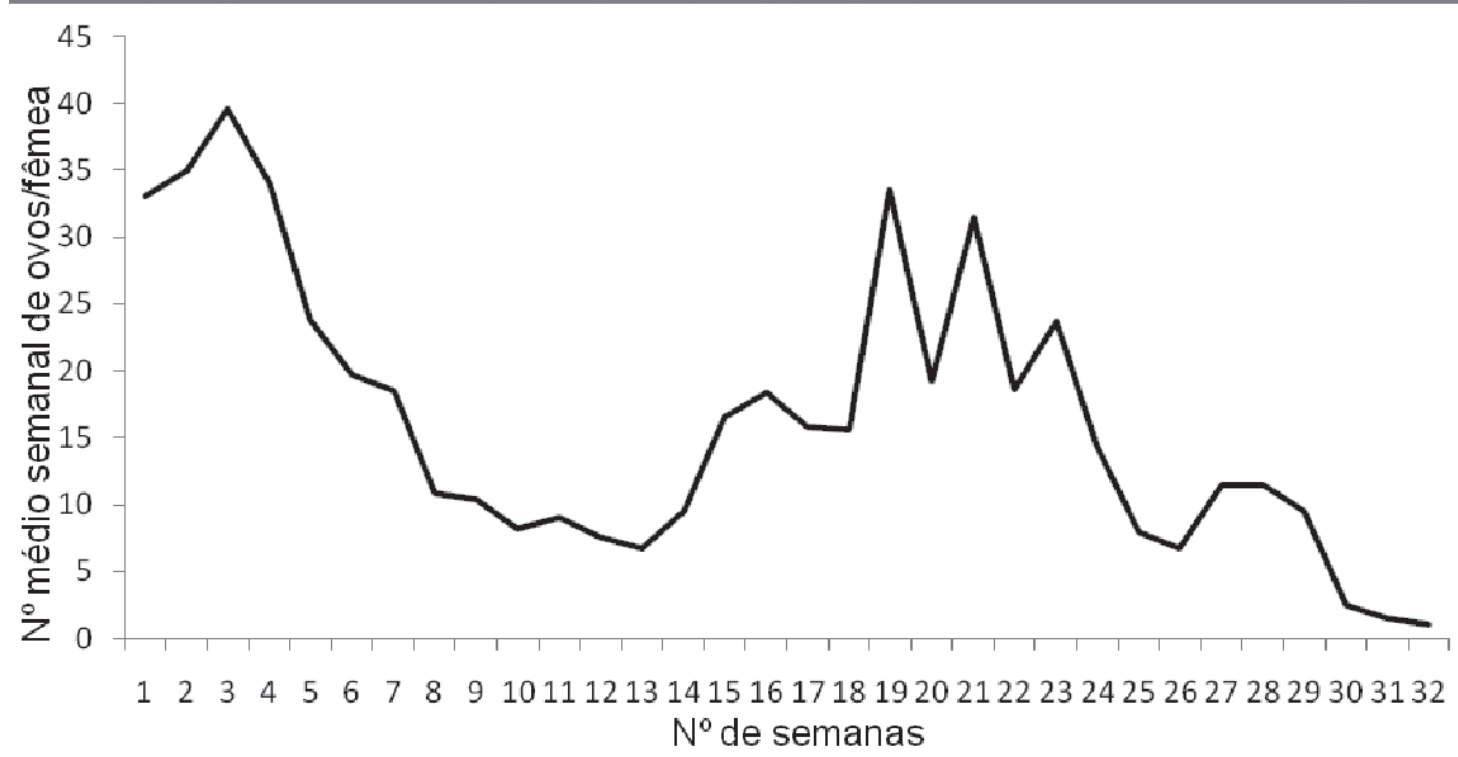

FIGURA 2- Número médio semanal de posturas realizado por fêmea de Conotrachelus psidii em frutos de goiabeira (Psidium guajava), em condições de laboratório. 


\section{CONCLUSÕES}

O desenvolvimento da técnica de manutenção de pré-pupas e pupas de Conotrachelus psidii permite acompanhar diariamente o desenvolvimento de prépupas, pupas e adultos do gorgulho-da-goiaba, sem que eles necessitassem reconstruir uma nova câmara, mostrando ser menos estressante e menos onerosa do ponto de vista energético.

\section{AGRADECIMENTOS}

Aos órgãos fomentadores, INCT HYMPAR SUDESTE/CNPq/FAPESP/CAPES.

Ao Dr. Sérgio Antônio Vanim, do Museu de Zoologia da Universidade de São Paulo, pela confirmação da espécie.

\section{REFERENNCIAS}

AGROFIT 2013. Disponível em: < http://agrofit. agricultura.gov.br/agrofit cons/principal_agrofit cons $>$. Acesso em: 25 fev. 2013.

BAILEZ, O. E.; VIANA-BAILEZ, A. M.; DE LIMA J. O. G.; MOREIRA, D. O. Life - history of the guava weevil Conotrachelus psidii Marshall (Coleoptera: Curculionidae) under laboratory conditions. Neotropical Entomology, Londrina, v. 32, n. 2, p. 203-207, 2003.

KOYAMA, J.; KAKINOHANA, H.; MIYATAKE, T. Eradication of themelon fly, Bactrocera cucurbitae, in Japan: Importance of behavior, ecology, genetics, and evolution. Annual Review of Entomology, Stanford, v.49, p. 331-349, 2004.

MARTÍNEZ, N. B.; CÁSARES, R. Distribución en el tiempo de las fases del gorgojo de la guayaba Conotrachelus psidii Marshall (Coleoptera: Curculionidae) en el campo. Agronomía Tropical, Venezuela, v.31, n. 1-6, p. 123-130, 1981.
MONROY, R. A.; INSUASTY, O. I. Biología del Picudo de la guayaba Conotrachelus psidii (Marshall) (Coleoptera: Curculionidae). Revista Corpoica - Ciencia y Tecnología Agropecuaria, Colômbia, v.7, n.2, p.73-79, 2006.

PAIVA, M. C.; FIORAVANÇO, J. C.; MANICA, I. Características físicas dos frutos de quatro cultivares e duas seleções de goiabeira no $5^{\circ}$ ano de produção em Porto Lucena - Rio Grande do Sul. Ciência Rural, Santa Maria, v. 25, n. 2, p. 209-213, 1995.

PEREIRA, É. F.; LOPES, J. R. S.; TURATI, D. T.; MUNHOZ, C.; CORRENTE, J. E. Influência das condições hídricas do solo e da temperatura na sobrevivência e alimentação de Oncometopia facialis (Hemiptera: cicadellidae) em "seedlings" de citros. Arquivos do Instituto Biológico, São Paulo, v.72, p.343-351, 2005.

SAXTON, K. E.; RAWLS, W. J. Soil water characteristic estimates by texture and organic matter for hydrologic solutions. Soil Science Society of America Journal, Madison, v.70, p.1569-1578, 2006.

VASQUEZ, J.; DELGADO, C.; FERRERO, D. M. Les insectes nuisibles au goyavier (Psidium guajava L.) en Amazonie péruvienne. Fruits, Paris, v.57, n.5, p.323-334, 2002.

VIANA, P. A.; COSTA, E. F. da. Efeito da umidade do solo sobre o dano da lagarta-elasmo, Elasmopalpus lignosellus (Zeller) na cultura do milho. Anais da Sociedade Entomológica do Brasil, Londrina, v. 24, p. 209-214, 1995. 